\title{
ANÁLISE DISCURSIVA DAS REPRESENTAÇÕES SOCIAIS DE IDOSOS SOBRE SUAS TRAJETÓRIAS DE VIDA'
}

\author{
Janaína da Silva Gonçalves Fernandes² \\ José Maria Montiel ${ }^{3}$ \\ Márcia Siqueira de Andrade ${ }^{4}$ \\ Daniel Bartholomeu ${ }^{5}$ \\ Juliana Francisca Cecato ${ }^{6}$ \\ José Eduardo Martinelli?
}

1 Trabalho desenvolvido com o apoio da Coordenação de Aperfeiçoamento de Pessoal de Nível Superior do Ministério da Educação, Brasil.

2 Graduada em Psicopedagogia. Mestre em Psicologia Educacional. Bolsista CAPES e Doutoranda do Programa de Pós-Graduação em Psicologia Educacional do Centro Universitário FIEO. E-mail: janainagoncalves80@yahoo.com.br.

3 Graduado em Psicologia. Doutor em Avaliação Psicológica em Contexto de Saúde Mental. Professor do Programa de Pós-Graduação em Psicologia Educacional do Centro Universitário FIEO. E-mail: montieljm@hotmail.com.

4 Graduada em Educação Artística. Doutora em Psicologia da Educação. Professora e Coordenadora do Programa de Pós-Graduação em Psicologia Educacional do Centro Universitário FIEO. E-mail: mandrade@unifieo.br.

5 Graduado em Psicologia. Doutor em Avaliação Psicológica em Contexto de Saúde Mental. Professor do Programa de Pós-Graduação em Psicologia Educacional do Centro Universitário FIEO. E-mail: daniel.bartholomeu@gmail.com.

6 Graduada em Biologia e Psicologia. Mestre em Ciências da Saúde. Professora do curso de Pós-Graduação Lato Sensu do UNISAL - Americana. E-mail: cecatojuliana@hotmail.com.

7 Graduado em Medicina. Doutor em Educação. Professor do Programa de Pós-Graduação em Ciências da Saúde da Faculdade de Medicina de Jundiaí. E-mail: drmartinelli@hotmail.com. 
resumo

O objetivo deste estudo foi identificar e analisar as representações sociais dos idosos sobre as suas trajetórias de vida. Utilizou-se como procedimento metodológico a história oral, sob a perspectiva de trajetória de vida. Foram realizadas entrevistas semiestruturadas com sete idosos entre 65 e 86 anos de idade, participantes de grupos de ensino formal em instituição particular localizada na região oeste da Grande São Paulo. Os idosos foram entrevistados individualmente e os dados foram submetidos à análise utilizando o software IRAMUTEQ. Destacaram-se, entre os temas de análise, cinco tipos de representações sociais na trajetória de vida desses idosos: aprendizagem, respeito, mudanças, família e fatos marcantes. Considerou-se que os idosos possuem forças para sonhar e acreditar no aprendizado contínuo e ininterrupto ao longo da vida. Assim, é necessário o desenvolvimento de propostas interventivas educacionais com propostas inovadoras, respeitando as características singulares da população idosa.

palavras-chave

Aprendizagem. Envelhecimento. História Oral. Narrativas. Representações Sociais.

O tema envelhecimento humano vem sendo debatido na literatura científica dos últimos anos, com diversas abordagens que destacam que o envelhecimento acarreta transformações e implicações tanto para a sociedade como para os indivíduos que se encontram nessa fase da vida (BEZERRA; ALMEIDA; NÓBREGA-THERRIEN, 2012; CALDAS, 2011; FIGUEIREDO, 2007; TAHAN; CARVALHO, 2010). O extenso interesse pelo tema do envelhecimento humano deve-se aos acréscimos demográficos da população de idosos, visto que, segundo estimativas do Instituto Brasileiro de Geografia e Estatística (2012), no Brasil, por exemplo, a população de idosos deve ultrapassar o número de 14,9 milhões em 2013 para 58,4 milhões em 2060. Com esse acréscimo, amplia-se o interesse e a preocupação dos indivíduos de compreender o fenômeno do envelhecimento e os possíveis impactos na sociedade.

Brandão (1998) explica que, ao buscar-se compreender o fenômeno atual ou do tempo presente, percebem-se contradições quando se trata do indivíduo 
idoso, uma vez que o tempo deles é o tempo antigo, antes de a sociedade os julgar como velhos, o passado é que identifica as suas relações com as pessoas e com o mundo, bem como a complexa integração com a sociedade contemporânea. Costa (2011) esclarece que, para se situar no mundo atual, os idosos necessitam se apropriar de uma fala não estigmatizada, que pode ser desenvolvida com o poder da linguagem oral na convivência social, possibilitando a sua reconstrução identitária e conquistas pessoais. Mas, para compreender-se o ser humano, não é possível separar a razão da emoção, ou seja, o subjetivo do cognitivo, bem como o individual do social, sendo imprescindível analisar a fala do idoso com o apoio de um estudo articulado dos elementos que estruturam as suas representações sociais.

De acordo com a concepção de Moscovici (2012), em quaisquer tipos de interações, sejam elas entre dois indivíduos ou entre dois grupos, está implicada a construção de representações; desse modo, as representações sociais podem ser definidas como partilhadas e reproduzidas socialmente, apresentando uma constância e objetividade, que permitem a cristalização de ações mútuas entre os grupos, constituindo, dessa maneira, as instituições que dominam as representações que, por sua vez, pressionam o indivíduo a se moldar a estas representações. Essas instituições e representações formam-se em diferentes espaços sociais, por meio de interações e comunicações cotidianas no interior dos grupos, construindo distintas mentalidades individuais que correspondem à sociedade ou cultura de pertença.

A constituição das representações sociais é elaborada a partir do senso comum, surgindo de um processo da interação de dois mecanismos internos simultâneos e de natureza psicológica e social que são denominados com objetivação e ancoragem. Na objetivação, as ideias abstratas transformam-se em imagens concretas por meio do reagrupamento de ideias e imagens enfocadas no mesmo tema, de modo a registrar o objeto no mundo do indivíduo. Já a ancoragem, une-se à identificação da imagem criada pela objetivação, sendo que estas novas imagens se unem às anteriores, inserindo-se ao pensamento pré-existente e reconhecido socialmente, permitindo, desse modo, a nomeação e a classificação de novos conceitos (JODELET, 1986; MOSCOVICI, 2012).

Moscovici (2012) explica que como os processos de objetivação e ancoragem são indissociáveis e ocorrem em constante movimento, eles proporcionam maneiras de se lidar com a memória, uma vez que a objetivação materializa a imagem ou a ideia e a direciona para o mundo exterior, enquanto a ancoragem mantém as ideias para dentro ao transformar o não familiar em familiar e transferi-lo para a sua esfera individual. Portanto, as representações comuns são pertinentes para a compreensão do coletivo ao se observar e registrar as 
regularidades observadas, sendo cruciais para a compreensão da história pessoal. Nesse sentido, a Teoria das Representações Sociais tem como objetivo compreender como os indivíduos ou grupos constroem um mundo estável e previsível a partir de suas histórias singulares.

Para compreender-se as representações sociais construídas pelos idosos, durante as suas trajetórias de vida, será utilizado neste estudo o procedimento metodológico da história oral para a coleta dos dados, por possibilitar o contato direto com os idosos, a sua história e o seu contexto; acrescenta a impossibilidade de se estabelecer procedimentos sistemáticos, prévios, estáticos e generalistas (ALBERTI, 2005). Como as representações sociais "[...] são trazidas pelas palavras e veiculadas em mensagens" (JODELET, 2001, p. 17), a narrativa oral colabora para o resgate da memória pessoal e igualmente social, ou seja, a memória psicossocial (BOSI, 1994).

Ao partir-se dos pressupostos anteriormente expostos, pode-se considerar a hipótese de que o idoso possui representações sociais que foram contidas durante a sua trajetória de vida, e que as alterações de grupos ou realidades nos contextos socioculturais que eles vivenciaram automaticamente também podem ter alterado as suas representações. (MARTINS; CAMARGO; BIASUS, 2009). Desse modo, este estudo tem como objetivo identificar e analisar as representações sociais de idosos sobre as suas trajetórias de vida, por meio da narrativa oral.

\section{Método}

Optou-se como proposta metodológica pela história oral na perspectiva das trajetórias de vida, por acreditar-se pela riqueza dos procedimentos oferecidos para a captação da dinâmica da narrativa. Assim, o idoso tem liberdade para narrar, o mais livremente possível, a respeito de suas experiências pessoais, conforme a sua vontade, sua natureza e suas condições.

\section{Campo da pesquisa}

O estudo foi realizado em instituição particular de ensino localizada na região oeste da Grande São Paulo. Essa instituição oferece curso universitário para indivíduos com cinquenta anos ou mais de idade. 
Foram convidados para participarem da pesquisa sete idosos, com idades entre 65 e 86 anos, sendo quatro mulheres e três homens. Como critério de inclusão, foi estabelecido serem incluídos na amostra os idosos com mais de 65 anos, que participavam de atividades em ensino formal. A maior parte dos entrevistados tinha curso universitário, constituindo $57 \%$ da amostra, seguida de $29 \%$ com curso técnico equivalente ao ensino médio e um afirmou ter completado o curso ginasial. Quanto ao estado civil, 43\% eram viúvos, $29 \%$ eram casados, $14 \%$, solteiro e idêntico percentual para divorciado. No que diz respeito à ocupação atual, 57\% frequentam o curso da Universidade da Maior Idade, 29\% são professores e um declarou trabalhar como coordenador de curso. Sobre o tema religião, 57\% informaram serem católicos, 29\% eram católicos praticantes e um afirmou ser espírita.

\section{Instrumentos}

Utilizou-se um roteiro de entrevista semiestruturado que serviu como guia, não sendo administrado de forma rígida, incentivando um clima favorável para que o idoso narre a sua trajetória de vida e um questionário sociodemográfico para a caracterização do grupo. As entrevistas foram audiogravadas, procedimento este realizado pela própria pesquisadora, com prévia autorização dos entrevistados. Quatro questões foram propostas a cada participante, na seguinte ordem: "Quais as suas lembranças da infância e das demais fases da sua vida?", "Conte com suas palavras algo que considera que foi marcante na sua vida.", "Tem alguma coisa que você teria mudado ou teria feito diferente ao longo da sua vida?" e “O que orientou as suas escolhas na sua trajetória de vida?". Essas questões procuraram contemplar dados subjetivos de como os idosos lidaram com as perdas e os ganhos vividos durante as suas trajetórias de vida.

\section{Procedimentos de coleta de dados}

O estudo foi aprovado pelo Comitê de Ética em Pesquisa do Centro Universitário FIEO, projeto de pesquisa no 352.689/2013, e todos os participantes assinaram um Termo de Consentimento Livre e Esclarecido antes de sua inclusão na pesquisa. Nos dias e horários estabelecidos, realizaram-se as entrevistas 
individuais em local reservado e escolhido pelo próprio idoso. Foi solicitado ao participante que narrasse sua trajetória de vida. $\mathrm{O}$ tempo de duração da entrevista correspondeu a uma média de 34 minutos para cada participante.

\section{Procedimentos de análise dos dados}

Para análise dos dados, utilizou-se o software IRAMUTEQ (Interface de $\mathrm{R}$ pour les Analyses Multidimensionnelles de Textes et de Questionnaires), que foi desenvolvido como ferramenta auxiliar do processo de codificação dos elementos trazidos por meio da coleta de dados (MUTOMBO, 2013). O referido programa, além de permitir uma análise lexical quantitativa que considera a palavra como unidade, também oferece a sua contextualização no corpus ou na entrevista. Cada entrevista é composta por conteúdos semânticos, que formaram o banco de dados ou corpus analisado pelo software. Realizou-se uma Análise da Classificação Hierárquica Descendente (CHD), que permite a análise das raízes lexicais e oferece os contextos em que as classes estão inseridas, de acordo com o segmento de textos do corpus da pesquisa (CAMARGO; JUSTO, 2013). Deste vocabulário, ou seja, as palavras e a sua contextualização dentro das unidades de contexto elementares (UCE), realizar-se-á uma análise de conteúdo (NASCIMENTO; MENANDRO, 2006). Nesse sentido, as classes que foram levantadas representam o espaço de sentido das palavras e podem sugerir elementos pertencentes às representações sociais (SILVA; BOUSFIELD; CARDOSO, 2013).

\section{Resultados e discussões}

O corpus analisado da pesquisa é composto por sete unidades de contexto iniciais (UCI) ou entrevistas, que o programa repartiu em 97 segmentos de unidades de contexto elementares (UCE), que continham 809 palavras ou formas distintas que ocorreram 3379 vezes, com uma frequência média de ocorrência de $4,17 \%$ por palavra e uma frequência média de $34,84 \%$ de ocorrência por seguimento. A análise hierárquica reteve $22 \mathrm{UCE}$, ou seja, foram consideradas $77,32 \%$ das UCE ( $\mathrm{n}=75)$. Após a redução dos vocábulos às suas raízes, obtiveram-se 590 lematizações, que resultaram em 469 palavras ou formas ativas analisáveis.

No primeiro momento, o corpus Trajetória de Vida foi dividido em dois subcorpus, por meio da classificação hierárquica descendente, estabelecendo cinco classes de segmentos de textos distintas. Em um segundo momento, um 
subcorpo foi dividido em dois, obtendo-se as classes 2 e 4 . Em um terceiro momento, houve outras divisões que originaram, de um lado, as classes 1 e 3 e, do outro lado, as classes 2 e 4. Em cada uma das classes, é apresentada no dendograma (ver Figura 1) a categorização da classe, o valor percentual em relação ao total do corpus analisado, as palavras que compõem as respectivas classes, a frequência $(f)$ de palavras dentro da classe, bem como a indicação do grau de significância das palavras que possuem mais afinidade com a classe, por meio da associação com o qui-quadrado $\left(\mathrm{x}^{2}\right)$, (MUTOMBO, 2013).

Figura 1 - Dendograma representativo das repartições em classes, percentagem, frequência das palavras e grau de significância da palavra com a classe das representações sociais de idosos sobre as suas trajetórias de vida.

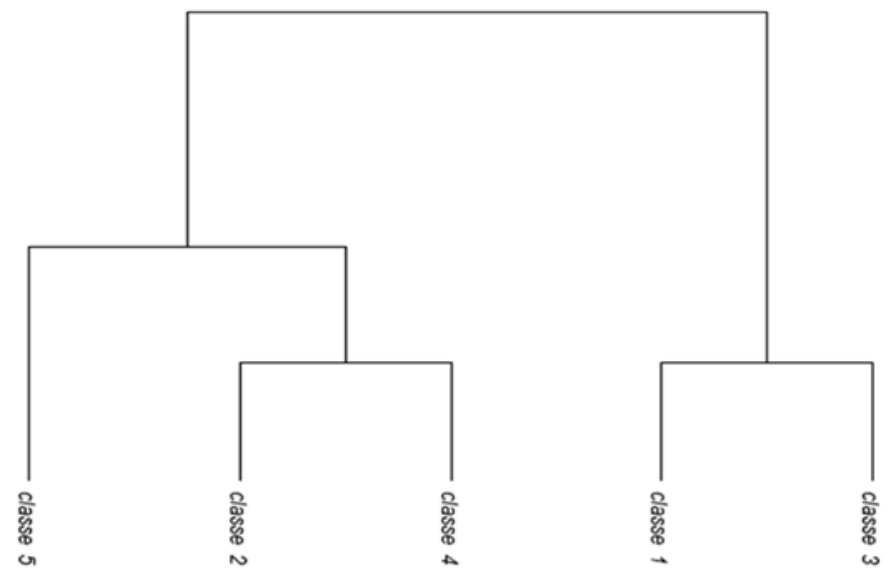

\begin{tabular}{|c|c|c|c|c|c|c|c|c|c|c|c|c|c|c|}
\hline \multicolumn{3}{|c|}{$\begin{array}{l}\text { Aprendizagem } \\
14 \text { uce }(18,7 \%)\end{array}$} & \multicolumn{3}{|c|}{$\begin{array}{c}\text { Respeito } \\
13 \text { uce }(17,3 \%)\end{array}$} & \multicolumn{3}{|c|}{$\begin{array}{c}\text { Mudanças } \\
13 \text { uce }(17,3 \%)\end{array}$} & \multicolumn{3}{|c|}{$\begin{array}{c}\text { Família } \\
16 \text { uce }(21,3 \%)\end{array}$} & \multicolumn{3}{|c|}{$\begin{array}{c}\text { Fatos marcantes } 19 \\
\text { uce }(25,3 \%)\end{array}$} \\
\hline Palavras & f & $\mathrm{X} 2$ & Palavras & $f$ & $\mathrm{X} 2$ & Palavras & $f$ & $\mathrm{X} 2$ & Palavras & $f$ & $\mathrm{X} 2$ & Palavras & $f$ & $\mathrm{X} 2$ \\
\hline *começar & 6 & 28,4 & *hoje & 6 & 20,7 & ${ }^{*}$ formar & 5 & 19,8 & *mãe & 8 & 23,6 & ${ }^{*}$ vida & 13 & 20,6 \\
\hline *estudar & 9 & 23,5 & *respeito & 4 & 20,1 & *mudar & 4 & 14,6 & ${ }^{*}$ pai & 8 & 20,2 & $\begin{array}{l}\text { *acon- } \\
\text { tecer }\end{array}$ & 5 & 15,7 \\
\hline *pouco & 4 & 18,4 & mulher & 3 & 14,9 & sozinho & 3 & 9,8 & *casar & 7 & 19,4 & coisa & 8 & 9,2 \\
\hline querer & 5 & 14,1 & muita & 4 & 14,6 & jeito & 3 & 9,8 & infância & 5 & 14,9 & bastante & 3 & 9,2 \\
\hline vir & 3 & 13,6 & graça & 4 & 14,6 & sempre & 5 & 8,5 & minha & 13 & 14,4 & marcar & 4 & 8,4 \\
\hline
\end{tabular}




\begin{tabular}{ll|l|l|lll|lll}
\hline Continuaçāo & & & ano & 10 & 8,7 & família & 5 & 6,5 \\
\hline & & & & & lembrar 3 & 7,2 & minha & 12 & 5,6 \\
\hline & & & & & & & geografia & 3 & 5,5 \\
\hline
\end{tabular}

* Grau de significância da palavra com a classe de $<0,0001$.

O dendograma (ver Figura 1) apresenta categorias que se tornaram nítidas pelos trechos dos depoimentos, que exibe marcos que concentram a significação e o sentido dos relatos. Para respeitar a classificação hierárquica descendente, que emergiu por meio do processamento dos depoimentos dos idosos com o apoio do software IRAMUTEQ, a apresentação dos resultados e das discussões discorre conforme a divisão e ordem estabelecida pelo programa. São também apresentadas as relações das palavras que emergiram nas classes entre si, no formato de recortes do corpus utilizando as UCE mais significativas de cada classe.

A classe 5, categorizada como Aprendizagem, emerge como foco principal para iniciar a apresentação das narrativas da trajetórias de vida dos idosos participantes da pesquisa, uma vez que essa classe é a base para a formação das outras, a qual abrange 18,67\% do total das UCE, do total de depoimentos analisados. Seu conteúdo semântico sugere que o estudo formal foi um elemento marcante nas narrativas destes idosos.

As UCE captaram trechos em que o ingresso no mercado de trabalho de alguns idosos aconteceu devido à exploração do trabalho infantil, que era uma realidade no contexto histórico-social que estes idosos testemunharam, como se pode perceber em suas narrativas:

Comecei a trabalhar em um emprego que eu não queria. Meu pai quem arrumou. (Idosa de 71 anos).

Saí de casa com 12 anos porque queria estudar. (Idosa com 72 anos).

Saí da escola e comecei a trabalhar no pasto para ajudar a família." (Idoso de 86 anos).

Ao apreender-se os sentidos atribuídos à pessoa velha, construídos por idosos, Santos, Tura e Arruda (2013) verificaram que o termo experiência é um possível produtor do sistema central da representação. Com esse resultado, pode-se inferir que, ao se associar aprendizagem à velhice, faz-se necessário 
considerar que o idoso, além de experiente, ainda continua em um processo ininterrupto de aprendizagem, como pode-se observar em algumas UCE que representam esta classe:

Comecei a estudar já na fase adulta e não parei mais [...]. O que me orienta é a curiosidade de querer saber sempre um pouco mais. (Idoso de 65 anos).

Vim estudar um pouco tarde, perdi muito tempo em outros caminhos. (Idoso de 69 anos).

Apesar de vivenciarem um princípio conturbado e experienciarem diversas adversidades ao longo de suas trajetórias de vidas, estes idosos ainda possuem forças para sonhar e acreditar que aprender é o caminho para se viver bem, consigo mesmo e com os outros. Desse modo, os idosos procuram transmitir os seus conhecimentos a suas futuras gerações:

Cada filho tem sua profissão, consegui o que eu queria. (Idosa de 69 anos).

Como o desenvolvimento da inteligência e da criatividade está relacionado com a escolaridade, por melhorar o desempenho das atividades cognitivas e o bem-estar (CUNHA, 2011; SOUZA; WECHSLER, 2013), uma das idosas nos transmite a sua experiência:

\section{Eu fiz o eu que quis, estudei. (Idosa de 69 anos).}

Mesmo que esses idosos narrem os obstáculos que cercaram o aprendizado no princípio de suas vidas, pode-se sugerir que o aprender é um querer nas representações sociais desses idosos. Esse desejo de aprender pode estar relacionado com a necessidade de se sentir respeitado e com a possibilidade de transmitir suas experiências e seus conhecimentos nos tempos atuais, como pode-se verificar nas próximas duas classes (classes 2 e 4), que se originaram da categoria Aprendizagem.

Tanto a classe 2 como a classe 4 abrangem 17,33\% cada uma do total das UCE dos depoimentos analisados. A classe 2, categorizada como Respeito, abrange representações sobre o respeito ao idoso nos dias de hoje, em que se ressalta o respeito à figura da mulher. Já a classe 4, categorizada como Mudanças, mostra as representações sociais dos idosos como indivíduos com capacidade de formar e transformar realidades, mesmo com as adversidades com que se deparam na fase do envelhecimento. No outro extremo do dendograma (Figura 
1), as outras duas classes que emergem também são associadas à classe 5 , que foi categorizada como Aprendizagem, complementando as representações sociais dos idosos sobre as suas trajetórias de vida.

Os conteúdos da segunda e da quarta classes da análise hierárquica (ver Figura 1) mencionam uma representação social que se centra principalmente nos elementos respeito e formação de novos valores para enfrentamento das mudanças que se processam no decorrer dos tempos. Sugerem que o idoso que tem possibilidades de se adaptar e acompanhar as mudanças sociais dinâmicas pode conquistar o respeito almejado.

Dos conteúdos lexicográficos contidos nos depoimentos dos idosos da classe 2, emergiram narrativas que exemplificam a representação social objetivada (MOSCOVICI, 2012) dos idosos do elemento respeito:

Naquela época, o professor era uma profissão de respeito. (Idoso de 69 anos).

A gente tem que falar e eles têm que obedecer. Eu fui criada assim. (Idosa de 65 anos).

Outro elemento que requer atenção na categoria 2 é a representação social ancorada (MOSCOVICI, 2012) de respeito pela mulher:

Os antigos achavam que mulher não precisava estudar. Bastava saber assinar para casar. (Idosa com 72 anos).

Achei que não era um ideal um homem fazer o curso Normal. (Idoso de 69 anos).

Os idosos deste contexto histórico-social testemunharam em suas trajetórias de vida representações sociais baseadas no senso comum e, simultaneamente, construídas no meio científico de que o gênero feminino integra um grupo social pertencente a uma classe social desfavorecida. Nas narrações desses idosos, percebe-se que a mulher era excluída do estudo formal; as que insistiam em estudar eram direcionadas a cursos rotulados como exclusivos para o sexo feminino, como era o caso do curso Normal, também conhecido como Magistério Pedagógico, do Sistema de Ensino Brasileiro.

Um estudo sobre as representações sociais do trabalho feminino para o homem casado (NASCIMENTO; GIANORDOLI-NASCIMENTO; TRINDADE, 2008) aponta que, embora a mulher contribua financeiramente com as despesas do lar, possui o papel cristalizado de mãe e de esposa que lhe atribui o dever 
das tarefas domésticas, em que a dupla jornada é consequência do mérito do direito de ter um trabalho que lhe satisfaça. Outro estudo considerou que a valorização igualitária social do trabalho na percepção das mulheres acontece com o retorno financeiro, enquanto que o estudo implica a formação dos valores morais (ARAÚJO; SCALON, 2006). Portanto, mesmo com as conquistas a favor do sexo feminino nos tempos atuais, como é o caso do direito ao trabalho fora do lar, as representações sociais de desvalorização da figura da mulher continuam objetivadas nas representações desses idosos.

$\mathrm{Na}$ classe 4, que foi categorizada como Mudanças, pode-se notar que alguns idosos confirmam em trechos de seus depoimentos receio ou mesmo a impossibilidade de participar de mudanças:

Não teria nada que eu pudesse fazer para ter mudado esse quadro. (Idosa de 71 anos).

Você não sabe se tem estrutura para isso. Não acredita que pudesse mudar."(Idosa de 72 anos).

Não mudaria, sempre fui durona e sargentona, mas valeu a pena. (Idosa de 65 anos).

Esse quadro de resistência às mudanças suporta a necessidade de se proporcionar aos idosos a possibilidade de mudar a representação da fase do envelhecimento como uma fase de dependência e, ainda, contribuir para a possibilidade de o idoso vivenciar novas experimentações (ELIAS; PIZETI; BARRETO, 2013). No entanto, a mudança pode estar relacionada a uma situação forçada de perda, como se pode perceber no trecho a seguir, em que a participante explica o caminho que encontrou para lidar com a perda de um ente querido:

Confiava muito nele. Ficou muito difícil, mas tive que mudar muito. (Idosa de 69 anos).

Das UCE sobre mudanças, percebe-se que esses idosos se veem por meio das objetivações que lhe foram atribuídas (ELIAS; PIZETI; BARRETO, 2013), sem forças para lutarem contra as adversidades e possibilidades de mudanças, ressaltando que no sistema educativo que esses idosos vivenciaram, aplicavam-se medidas de correção antidemocráticas e agressões físicas (SILVA; 
JUNQUEIRA, 2013). Este controle rígido de conduta pode ter implicado representações sociais que influenciam os idosos a terem receio de mudanças. Por outro lado, as atitudes opressoras que esses idosos cultivaram durante as suas trajetórias de vida os fortaleceram no sentido de transmitirem os seus valores para os seus descendentes, como se pode observar nas UCE a seguir:

Formei-me nos trancos e barrancos, mas me formei. Por isso que fiz questão que meus filhos se formassem. (Idosa de 72 anos).

Às vezes, até pela falta do pai, ficamos mais mole ou mais durona na educação, mas todos estão formados. (Idosa de 69 anos).

A classe 1, categorizada como Família, envolve 21,34\% do total das UCE e expõe as lembranças dos idosos da convivência familiar. A classe 3, categorizada como Fatos Marcantes, abrange 25,33\% do total das UCE da globalidade de depoimentos analisados, parecendo ser, pela frequência de ocorrências e afinidades significativas com o conteúdo, a classe mais importante. A classe 3 inclui as representações sociais dos fatos marcantes que ocorreram nas trajetórias de vida dos idosos. Vale ressaltar que prevaleceu nesta categoria UCE de participantes do sexo masculino.

Na classe 1, que destacou a importância da família na construção da trajetória de vida do idoso, verificou-se nas UCE que as figuras de mãe e pai marcam a construção da trajetória de vida destes idosos. Esses dados revelam como esses idosos lidaram com os acontecimentos de perdas e sofrimentos nas fases da infância e da adolescência. Os valores familiares podem ter influenciado no enfrentamento das diversas situações com que eles se depararam, como se pode observar nas narrativas seguintes:

Não tive regalias na adolescência. Só podia sair com o meu pai e com a minha mãe. (Idosa de 71 anos).

Ajudava a cuidar dos irmãos menores e a minha mãe no serviço doméstico. (Idoso de 86 anos).

A minha infância maravilhosa foi quando eu vivi com a minha mãe. (Idosa de 72 anos).

O que me marcou foi a separação dos meus pais. (Idosa de 69 anos). 
Para manter uma faculdade naquela época, você tinha que ter um pai rico. (Idoso de 69 anos).

Os vínculos familiares também influenciaram a construção da trajetória de vida destes idosos, marcados por acontecimentos como o casamento, nascimento de filhos e a perda de entes queridos, como pode-se observar:

Casei e perdi minha esposa no dia em que fizemos 61 anos casados. (Idoso de 86 anos).

Sentia-me segura com ele, portanto fiquei desnorteada quando ele morreu, porque me casei muito cedo. (Idosa de 69 anos).

De acordo com as narrativas dos idosos, há uma estreita relação sobre o que foi vivido e o contexto histórico-social narrado, uma vez que a memória não é estática, pois sempre revisitam os tempos vivenciados marcados pelos lugares, traumas com um apelo do tempo presente (BOSI, 2003). Esse estreitamento vincula as classes categorizadas como Família (classe 1) e os Fatos Marcantes (classe 3) que aconteceram na trajetória de vida desses idosos.

Finalmente, a classe 3 da análise hierárquica categorizada como Fatos Marcantes é a mais importante do estudo, como já foi citado anteriormente, por envolver a maior parte do total das UCE das sete entrevistas analisadas. Essa classe indica uma representação social dos idosos sobre as suas trajetórias de vida a dois tipos de noções: "vida" e "acontecer". Estas duas noções encontram-se conectadas no sentido em que o que marca a vida dos indivíduos é a ocorrência de variados acontecimentos que produzem o caráter dinâmico das representações sociais em uma sociedade em transformação, que se inova em vias de se fazer e se refazer (MOSCOVICI, 2012).

Uma característica da última classe é que estes idosos não produzem ideias e imagens de representações somente negativas da sua trajetória de vida, mas de elaborações otimistas de agradecimento e apreciação do tempo vivido, que remete ao sentido de aceitação por parte dos idosos de sua própria história de vida singular, como pode-se notar nos trechos a seguir:

As lembranças são dos amigos e viagens, foram às coisas boas da vida, não posso me queixar. (Idoso de 65 anos).

Louvo e agradeço a Deus por tudo o que acontece na minha vida, porque é vida de gente pobre, mas muito feliz sem grandes pretensões. (Idoso de 86 anos). 
Embora os idosos aceitem os fenômenos que aconteceram em suas trajetórias de vida, outra característica marcante na classe 3 é o arrependimento por certos acontecimentos não realizados ou incompletos, devido à pressão das representações dominantes que existem nas sociedades, que estabelecem padrões culturalmente cristalizados aos quais os indivíduos são induzidos a se moldarem (MOSCOVICI, 2012), para conviverem bem consigo mesmos e com os outros. As UCE a seguir exemplificam o conteúdo das angústias que foram narradas pelos idosos:

Não que eu esteja arrependido de ter me casado, mas de ter me casado tão jovem. (Idoso de 65 anos).

Isso me marcou por eu não ter completado os meus estudos, mas não tive arrependimento, porque em primeiro lugar está a minha família. (Idoso de 86 anos).

Às vezes me arrependo. Fiz várias coisas na minha vida e minha trajetória foi meio tumultuada. (Idoso de 69 anos).

Esta ambivalência de sentidos positivos e negativos das trajetórias de vida desses emergiu nitidamente nesta última classe. $\mathrm{O}$ aspecto interessante da classe 3 é o fato dos participantes serem todos do sexo masculino; talvez este fato possa estar associado a uma representação social objetivada do sexo masculino, de que o homem deve ser o provedor, ter o poder (CORRÊA et al., 2007) e as expectativas perante a ele são as de ação, de fazer acontecer. Nesse sentido, esses idosos encontram na fase do envelhecimento a representação social ancorada no arrependimento, por falta de oportunidade de realizarem ou completarem a representação dos seus sonhos, restando-lhes o sentimento de frustração da representação social vigorante do significado de ser velho. $\mathrm{O}$ idoso com mais idade do grupo demonstra essa frustração na sua fala:

O idoso precisa viver, comprar remédio, pagar as suas prestações e os seus compromissos de um modo geral. A minha vida foi mais ou menos esta até chegar à idade média porque eu não sou velho, sou médio. (Idoso de 86 anos).

Todo esse cenário apresentado no contexto do presente estudo foi manifestado por meio dos discursos que regulam, normalizam e instauram saberes que constroem as representações sociais dos indivíduos e grupos desta realidade (JUNIOR; FREITAS, 2012). 
O objetivo deste estudo foi identificar e analisar as representações sociais dos idosos sobre a sua trajetória de vida. Para isso, principiou-se com uma entrevista semiestruturada com os idosos sobre a elaboração das perdas e os ganhos vivenciados durante as suas trajetórias de vida. Os resultados indicaram cinco classes de representações sociais interligadas: a Aprendizagem que ofereceu base para todas as outras classes; o Respeito e as Mudanças que apresentaram o mesmo grau de significância no corpus; no outro extremo do dendograma (Figura 1), mas também derivadas da classe categorizada como Aprendizagem, emergiram as classes Família e Fatos Marcantes, sendo que esta última se revela a mais importante por apresentar a maior quantidade de UCE.

Na classe denominada Aprendizagem, observa-se que, embora os idosos narrem os obstáculos que cercaram o seus processos de aprendizado (exploração de trabalho infantil), o aprender é um querer nas representações sociais desses idosos, o que indica a necessidade de se sentirem respeitados nos tempos atuais (idosos e idosas), emergindo, desse modo, a segunda representação social, que oferece uma continuidade para, na terceira classe, representar os idosos como indivíduos com capacidade de formar e transformar realidades, mesmo com as adversidades (doença e perdas) com que se depararam na fase do envelhecimento.

No outro extremo das representações, mas também associadas à categoria Aprendizagem e complementando as representações sociais dos idosos sobre as suas trajetórias de vida, a classe denominada Família indica como os valores familiares influenciaram no enfrentamento das diversas situações de perdas e sofrimentos com que os idosos se depararam (opressão, separação) nas fases da infância e da adolescência. Esta classe também é marcada por acontecimentos que simbolizam as etapas da trajetória de vida dos idosos (casamento, nascimento de filhos, perda de entes queridos).

A última classe aponta Fatos Marcantes que ocorreram durante as trajetórias de vida dos idosos, em que despontaram ambivalências de sentidos positivos e negativos durante as suas trajetórias de vida. Uma característica desta classe é que estes idosos não produzem ideias e imagens de representações somente negativas da sua trajetória de vida, mas de elaborações otimistas de agradecimento e apreciação do tempo vivido, o que remete ao sentido de aceitação por parte dos idosos de sua própria história de vida singular, bem como sentimentos negativos de arrependimento.

Essas cinco classes de representações sociais sobre a trajetória de vidas dos idosos que emergiram podem auxiliar na reflexão sobre as condições que 
vêm marcando a experiência de envelhecer na contemporaneidade. Os idosos entrevistados aqui demonstraram que possuem forças para sonhar e acreditar no aprendizado ininterrupto ao longo da vida, mesmo que as sociedades contemporâneas não respeitem a formação de valores que esses indivíduos apreenderam dos acontecimentos significantes vivenciados durante as suas trajetórias de vida.

Portanto, ao promover-se a compreensão da aprendizagem como um processo contínuo e ininterrupto ao longo da vida de quaisquer indivíduos, podem-se originar mudanças nas representações sociais estereotipadas que excluem os idosos do desenvolvimento e aprimoramento da aprendizagem. É nesse contexto que aparece a necessidade do desenvolvimento de intervenções educacionais com propostas inovadoras que respeitem as características singulares dessa população e que promovam uma nova cultura de aprendizagem.

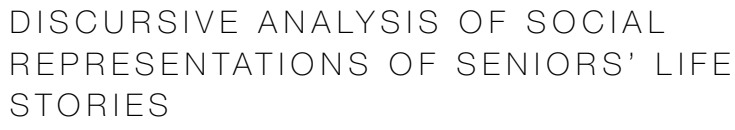

\section{abstract}

The objective of this study was to identify and analyze the social representations of seniors about their life stories. As methodological procedure, the oral history was used the was in the perspective of life stories. Semi-structured interviews with seven seniors aged between 65 and 86 years were conducted, with groups of participants from formal education in a private institution located in the western region of Greater São Paulo being organized. The elderly were interviewed individually and the data were subjected to analysis using the software IRAMUTEQ. Among the topics of analysis, five types of social representations in older people's life stories were highlighted: learning, respect, change, family and striking facts. We conclude elderly people have strength to dream and believe in continuous learning and uninterrupted lifelong, being necessary to develop interventional educational proposals with innovative proposals, respecting the singular characteristics of this population.

keywords

Learning. Aging. Oral History. Narratives. Social Representations. 
ALBERTI, Verena. Manual de história oral. 3. ed. Rio de Janeiro: FGV Editora, 2005.

ARAÚJO, Clara; SCALON, Celi. Gênero e a distância entre a intenção e o gesto. Revista Brasileira de Ciências Sociais, São Paulo, v. 21, n. 62, p. 45-68, out. 2006.

BEZERRA, Fernanda Carvalho; ALMEIDA, Maria Irismar de; NOBREGA-THERRIEN, Sílvia Maria. Estudos sobre envelhecimento no Brasil: revisão bibliográfica. Revista Brasileira de Geriatria e Gerontologia, Rio de Janeiro, v. 15, n. 1, p. 155-167, 2012.

BOSI, Ecléa. Memória e sociedade: lembranças de velhos. 3. ed. São Paulo: Companhia das Letras, 1994. Editorial, 2003.

O tempo vivo da memória: ensaios de psicologia social. Cotia: Ateliê

BRANDÃO, Carlos Rodrigues. A memória no outono. Psicologia USP, São Paulo, v. 9, n. 2, p. 297-310, 1998.

CALDAS, Célia Pereira. Revista Brasileira de Geriatria e Gerontologia: vários olhares sobre o envelhecimento. Revista Brasileira de Geriatria e Gerontologia, Rio de Janeiro, v. 14, n. 2, p. 195-196, abr./jun. 2011.

CAMARGO, Brigido Vizeu; JUSTO, Ana Maria. IRAMUTEQ: um software gratuito para análise de dados textuais. Temas em Psicologia, Ribeirão Preto, v. 21, n. 2, p. 513-518, dez. 2013.

CORRÊA, Alessandra Morgado Horta et al. Soldadinhos-de-chumbo e bonecas: representações sociais do masculino e feminino em jornais de empresas. Revista de Administração Contemporânea, Curitiba, v. 11, n. 2, p. 191-211, abr./jun. 2007.

COSTA, Patrícia Claudia da. O que se aprende além das letras: um estudo sobre a alfabetização de pessoas idosas. Revista Brasileira de Geriatria e Gerontologia, Rio de Janeiro, v. 14, n. 4, p. 721-730, out./dez. 2011.

CUNHA, Maria Isabel da. Aprendizagem ao longo da vida e avaliação do desempenho profissional. Avaliação, Campinas; Sorocaba, v. 16, n. 3, p. 559-572, nov. 2011.

ELIAS, Méri Vanessa; PIZZETI, Sidineia Aparecida; BARRETO, Danielle Jardim. Idosos em experimentação no circuito urbano: relato de uma experiência. Psicologia: Ciência e Profissão, Brasília, v. 33, n. 3, p. 746-757, 2013.

FIGUEIREDO, Vera Lygia Menezes. Oficina inventiva e os desafios do envelhecimento saudável. Revista do Departamento de Psicologia - UFF, Niterói, v. 19, n. 1, p. 255-257, 2007

INSTITUTO BRASILEIRO DE GEOGRAFIA E ESTATÍSTICA. Comunicação Social. Índice de envelhecimento no Brasil cresce de 31,7, em 2001, para 51,8 em 2011. In.

SIS 2012: acesso de jovens pretos e pardos à universidade triplicou em dez anos. Rio de Janeiro, IBGE: 28 nov. 2012. Disponível em: <http://saladeimprensa.ibge.gov.br/ noticias?id=1\&idnoticia=2268\&t=sis-2012-acesso-jovens-pretos-pardos-universidade-triplicou-dez-anos\&view=noticia>. Acesso em: 20 mar. 2013.

JODELET, Denise. La representacion social: fenômenos, concepto y teoria. In: MOSCOVICI, Serge (Org.). Psicología social, Il: Pensamiento y vida social. Psicología social y problemas sociales. Traducción de David Rosenbaum. Barcelona: Ediciones Paidós, 1986. p. 469-494.

Representações sociais: um domínio em expansão. In: JODELET, Denise (Org.). As representações sociais. Tradução de Lilian Ulup. Rio de Janeiro: EdUERJ, 2001. p. 17-44. 
JUNIOR, Alberto Malheiros; FREITAS, Silvane Aparecida de. Envelhecimento e consumo: as representações da velhice feminina no discurso midiático. Estudos Interdisciplinares sobre o Envelhecimento, Porto Alegre, v. 18, n. 2, p. 275-291, dez. 2013.

MARTINS, Claudia Regina Magnabosco; CAMARGO, Brigido Vizeu; BIASUS, Felipe. Representações sociais do idoso e da velhice de diferentes faixas etárias. Universitas Psychologica, Bogotá, v. 8, n. 3, p. 831-847, sept./dic. 2009.

MOSCOVICl, Serge. Representações sociais: investigações em psicologia social. Petrópolis: Vozes, 2012.

MUTOMBO, Emilie. A bird's-eye view on the EC environmental policy framing: Ten years of Impact assessment at the commission. INTERNATIONAL CONFERENCE ON PUBLIC POLICY, 1., 2013, Grenoble. Annals... Grenoble: ICPP, 2013. Disponível em: <http:// www.icpublicpolicy.org/IMG/pdf/panel17_s1_mutombo.pdf>. Acesso em: 20 mar. 2013.

NASCIMENTO, Adriano Roberto Afonso do; GIANORDOLI-NASCIMENTO, Ingrid Faria; TRINDADE, Zeidi Araújo. A representação social do trabalho feminino para homens casados. Mental, Barbacena, v. 6, n. 11, p. 145-164, jul./dez. 2008.

NASCIMENTO, Adriano Roberto Afonso do; MENANDRO, Paulo Rogério Meira. Análise lexical e análise de conteúdo: uma proposta de utilização conjugada. Estudos e Pesquisas em Psicologia, Rio de Janeiro, v. 6, n. 2, p. 1-17, 2. sem. 2006

SANTOS, Verônica Braga dos; TURA, Luiz Fernando Rangel; ARRUDA, Angela Maria Silva. As representações sociais de "pessoa velha" construídas por idosos. Saúde e Sociedade, São Paulo, v. 22, n. 1, p. 138-147, jan./mar. 2013.

SILVA, Henrique Salmazo da; JUNQUEIRA, Patrícia Grandino. Reflexões e narrativas (auto)biográficas sobre as relações intergeracionais: resultados de uma intervenção socioeducativa com mulheres idosas. Psicologia \& Sociedade, Belo Horizonte, v. 25, n. 3, p. 559-570, 2013

SILVA, Jean Paulo; BOUSFIELD, Andréa Barbará da Silva; CARDOSO, Luiza Herzmann. A hipertensão arterial na mídia impressa: análise da revista Veja. Psicologia e Saber Social, Rio de Janeiro, v. 2, n. 2, p. 191-203, jul./dez. 2013.

SOUZA, Adriana Aparecida Ferreira de; WECHSLER, Solange Muglia. Inteligência e criatividade na maturidade e velhice. Psicologia: Reflexão e Critica, Porto Alegre, v. 26, n. 4, p. 643-653, out./dez. 2013.

TAHAN, Jennifer; CARVALHO, Antonio Carlos Duarte de. Reflexões de idosos participantes de grupos de promoção de saúde acerca do envelhecimento e da qualidade de vida. Saúde e Sociedade, São Paulo, v. 19, n. 4, p. 878-888, out./dez. 2010

Recebido: 14/04/2014

Aceite Final: 14/08/2015 